\title{
Forest Dynamics with Sentinel 2 in Antanambe between 2005 and 2016 with the Snap Tool
}

\author{
Tsiorinantenaina René Rakotoarison 1,2,3*, Aimé Richard Hajalalaina1,2,3, \\ Elysa Nambinintsoa Safidinirina ${ }^{1}$
}

\begin{abstract}
${ }^{1}$ School of Management and Technological Innovation, University of Fianarantsoa, Fianarantsoa, Madagascar ${ }^{2}$ Laboratory of Computer Science and Mathematics Applied to Development, University of Fianarantsoa, Fianarantsoa, Madagascar ${ }^{3}$ Computer Science, Geomatics, Mathematics and Applications, Hosting Team Fianarantsoa, Fianarantsoa, Madagascar Email: ^rtsiorinantenaina@gmail.com
\end{abstract}

How to cite this paper: Rakotoarison, T.R., Hajalalaina, A.R. and Safidinirina, E.N. (2021) Forest Dynamics with Sentinel 2 in Antanambe between 2005 and 2016 with the Snap Tool. Advances in Remote Sensing, 10, 92-101.

https://doi.org/10.4236/ars.2021.103006

Received: July 30, 2021

Accepted: September 15, 2021

Published: September 18, 2021

Copyright $\odot 2021$ by author(s) and Scientific Research Publishing Inc. This work is licensed under the Creative Commons Attribution International License (CC BY 4.0).

http://creativecommons.org/licenses/by/4.0/

\begin{abstract}
In order to protect and sustainably manage the forest in Madagascar, which is currently one of the countries still covered by forests, it is essential to use technological advances, particularly with regard to remote sensing. It provides valuable data, and sometimes free with a wide range of spatial, spectral and temporal resolutions to meet the demands for information on forest resources that are increasingly numerous and requires ever increasing levels of accuracy. The present work presents a methodology for the analysis of forest dynamics in the Antanambe area for the period 2005-2016 for monitoring forest degradation in this forest area to be conserved. The Random Forest algorithm was used to classify a Sentinel 2 image collected on November 07, 2016 and compare with a classification result with LandSat 5 in 2005 to detect change. The per-pixel change detection of both results captured the change map to better interpret the situation.
\end{abstract}

\section{Keywords}

Random Forest, Detection Change, Remote Sensing, Forest, Madagascar

\section{Introduction}

The demands for information on forest ecosystems are increasing and require ever increasing levels of precision. This calls for technological advances, especially in mapping and remote sensing means (diversity and specificity of sensors and platforms) provide valuable, and sometimes free, data for a wide range of 
spatial, spectral and temporal resolutions [1]. There are several research works that are concerned with forest dynamics in Madagascar such as the works of [2] [3] [4] [5]. In 2007, the analysis of forest cover evolution in Madagascar is done by processing Landsat satellite images that cover the period 1990-2000-2005. This analysis gives for 1990, an area significantly less than 10.7 million hectares (RPP, 2014). This difference can relatively be identified by the fact that the 2007 analysis used a more strict determination of forest. This study estimates the total forest area to be about 9,990,000 hectares in 2000 and about 9,725,000 hectares in 2005, which means an annual deforestation rate of $0.83 \%$ for the period 1990 2000 and $0.53 \%$ between 2000 and 2005 [6]. However, this study presents an analysis of forest dynamics in the Mananara Nord Madagascar area for the period 2005-2016 with the Random Forest (RF) classification algorithm. Several studies have used and highlighted the effectiveness of the RF algorithm among existing algorithms. Based on the accuracy evaluation and visual interpretation of the resulting maps, Schneider (2012) claimed that RF is more effective than the maximum likelihood classifier and support vector machine classification. In this study, a Sentinel-2 image acquired on November 07, 2016 was used and compared to a classification result of the LandSat image in 2005 [7]. The results represent the statistics and mapping of the dynamics of the forests of Mananara Nord between 2005 and 2016.

\section{Materials and Methods}

\subsection{Study Area}

The Mananara Nord National Park is located in the northeastern part of Madagascar. More precisely, this area is located in the district of Mananara Nord and the region of Analanjorofo. Its geographical coordinates are oriented between latitude $16^{\circ} 10^{\prime} 00^{\prime \prime}$ and longitude $49^{\circ} 46^{\prime} 00^{\prime \prime}$. This part presents tropical rainforests. We simulated a sample on a part of this zone which the commune of Antanambe (Figure 1).

\subsection{Presentation of the Data}

A Sentinel-2 image is used that was acquired on November 07, 2016. The Sentinel-2 image comes directly from the European Space Agency (ESA) download site or more precisely in https://scihub.copernicus.eu.

The Sentinel-2 satellite is launched as part of the European Union's Copernicus program which is equipped with the MSI sensor, it consists of two satellites, Sentinel-2A and Sentinel-2B: the first was launched in June 2015 and the second in March 2016. Each of these satellites provides all-land observation every 5 days, $10 \mathrm{~m}$ to $60 \mathrm{~m}$ resolution. The MSI sensor will provide 13 spectral bands from visible to mid-infrared illustrated in Table 1.

In 2014, inventory work was carried out in Madagascar by [7] on forest stratification. Landsat 5 images are used for the year 2005. A classification result from this work was used in the study. 


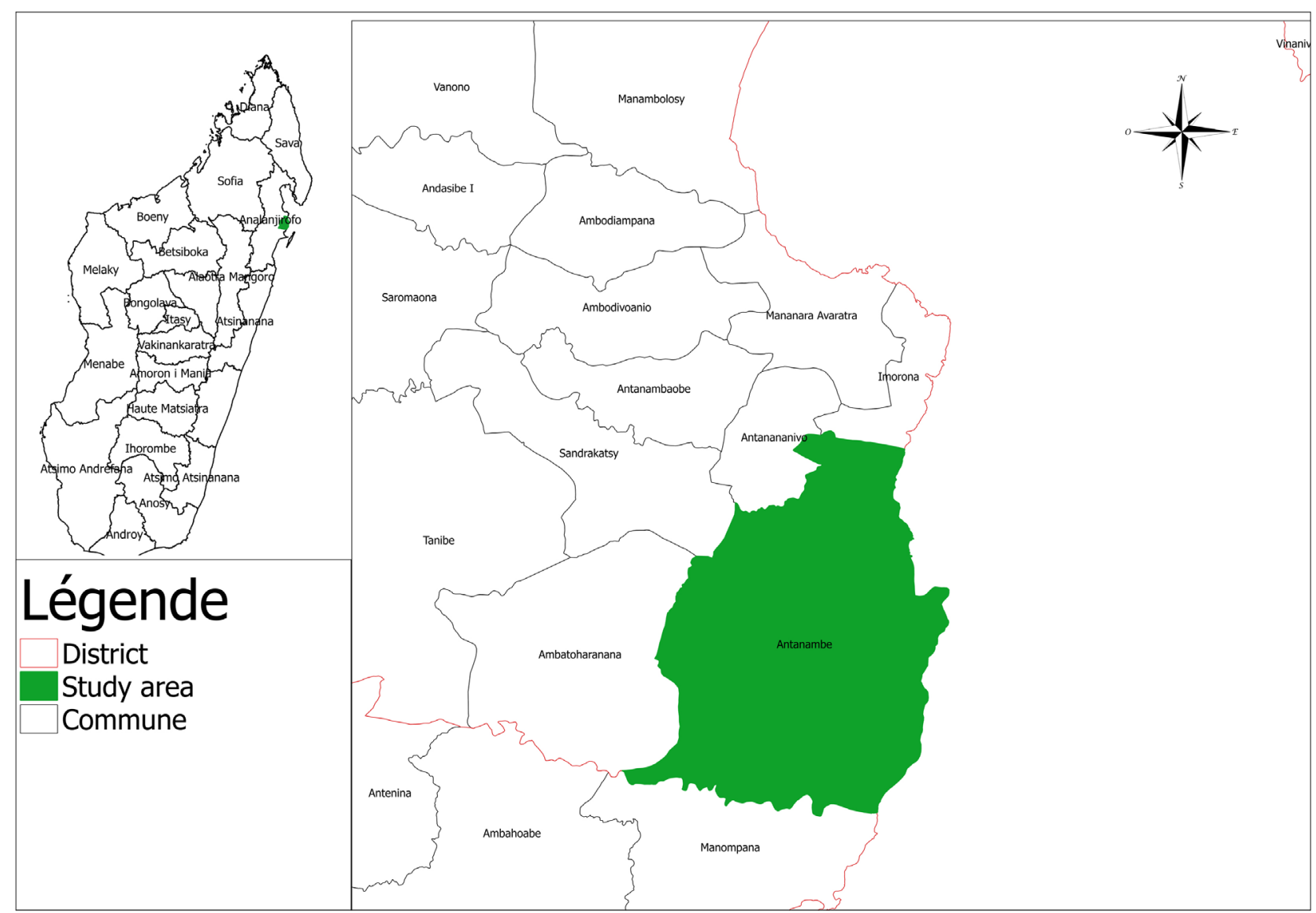

Figure 1. Study area.

Table 1. Sentinel-2 bands.

\begin{tabular}{cccc}
\hline Bands & Resolution $(\mathrm{m})$ & wavelength $(\mathrm{nm})$ & Width of the bands $(\mathrm{nm})$ \\
\hline B1 & 60 & 443 & 20 \\
B2 & 10 & 490 & 65 \\
B3 & 10 & 560 & 35 \\
B4 & 10 & 665 & 30 \\
B5 & 20 & 705 & 15 \\
B6 & 20 & 740 & 15 \\
B7 & 20 & 783 & 20 \\
B8 & 10 & 842 & 115 \\
B8A & 20 & 865 & 20 \\
B9 & 60 & 945 & 20 \\
B10 & 60 & 1375 & 30 \\
B11 & 20 & 1610 & 90 \\
B12 & 20 & 2190 & 180 \\
\hline
\end{tabular}

\subsection{Tool}

SNAP (Sentinel Application Platform) is an ESA product specifically for pro- 
cessing Sentinel images. SNAP contains Sentinel toolkits with common architectures developed by Brockmann Consult, SkyWatch and CS. SNAP is an open-source solution with a number of toolboxes and plugins.

\subsection{Methodology}

The Sentinel-2 image that we acquired is at pre-processing level 2a, i.e. it is no longer necessary to make the radiometric and geometric correction. We continue the pre-processing by combining the mono-spectral bands into a single multi-spectral band because when downloading Sentinel-2 images to the ESA site, the images are still separated into channels, so we need a transformation to obtain a multi-spectral image. Then, we cut the study area in order to minimize the processing time.

The NDVI thresholding technique is used for a pre-classification to discriminate vegetation to other land cover types [8]. NDVI values can range from -1 and 1. Higher values of the index correspond to the presence of dense and healthy vegetation cover. They are generally between 0.1 and 0.7 while clouds and snow result in NDVI values close to 0 [9].

The supervised classification [10] was used to determine the forest cover of the study area. We implemented the existing Random forest algorithm in the SNAP tool which is particularly effective in identifying relationships between a variable to be explained and explanatory variables [11].

To wait for the objective, we performed change detection between the 2016 classified Sentinel-2 image and the 2005 classification result from LandSat 5 [12] [13] [14]. The methodology is illustrated in Figure 2.

\section{Results and Discussions}

\subsection{Vegetation Index NDVI}

We have here a pre-classification result after the NDVI calculation. This index uses the near infrared band (PIR) and the red band (R) of the satellite image. In the case of Sentinel-2 images, the PIR is the eighth band and the $R$ is the fourth band.

$$
\mathrm{NDVI}=(P I R-R) /(P I R+R)
$$

By applying Equation (1), we have the result presented in Figure 3 where the higher values of the index correspond to the presence of a dense and healthy vegetation cover.

\subsection{Random Forest}

Supervised classification is used using the Random forest algorithm. It is a classification algorithm based on parallel learning on multiple decision trees that improves prediction accuracy [11]. After integrating the field validation points, the SNAP tool gave the confusion matrix presented in the Table 2 below, which deduces an acceptable Kappa index of 94, 8863\%. The result is presented in two classes (forest and non-forest) in Figure 4. 


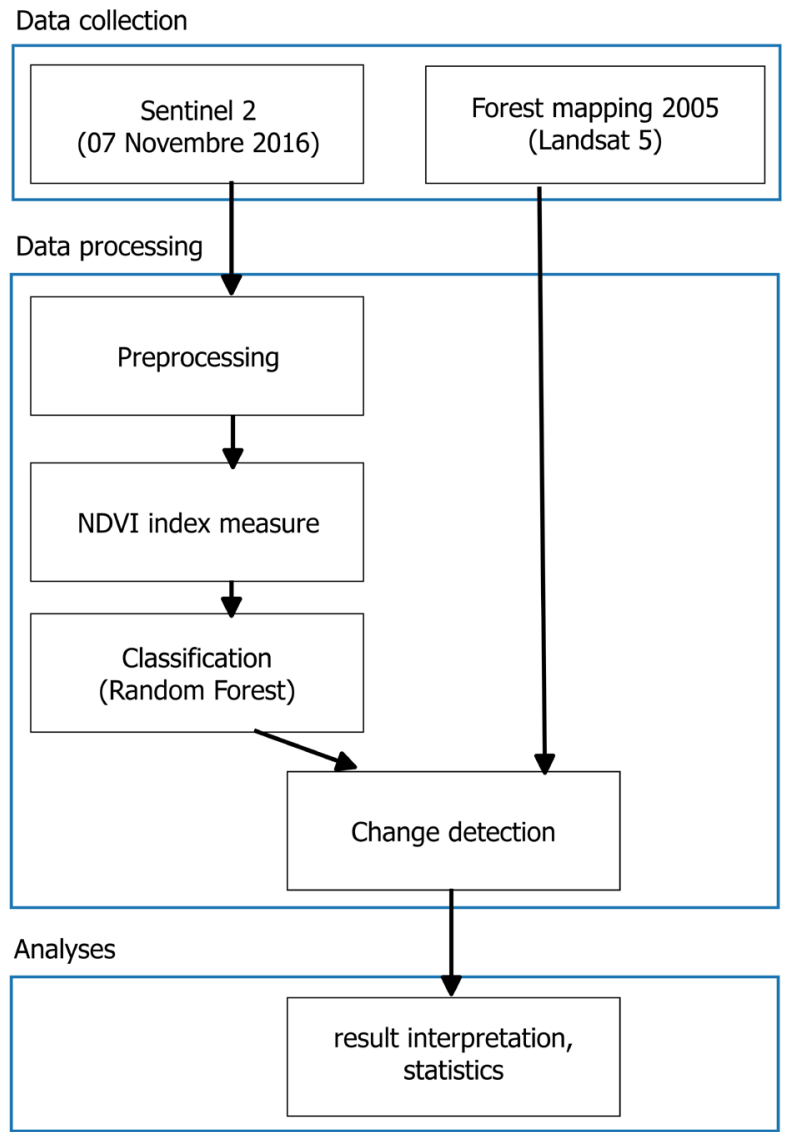

Figure 2. Methodology.

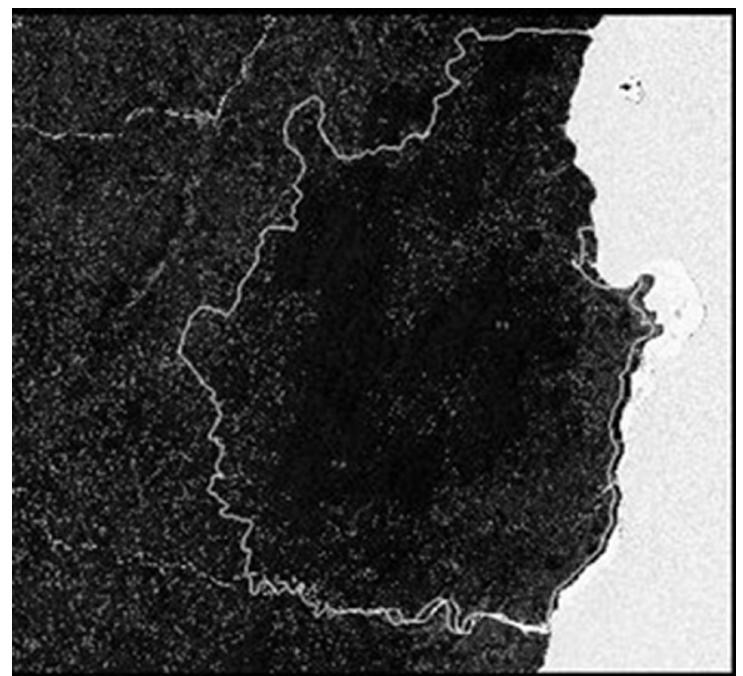

Figure 3. NDVI result.

Table 2. Confusion matrix.

\begin{tabular}{cccc}
\hline Classes & Forest & No forest & Production accuracy \\
\hline Forest & 99.31 & 1.76 & 60.38 \\
No forest & 0.69 & 98.24 & 39.62 \\
\hline
\end{tabular}




\subsection{Change Detection}

Change detection consists in comparing the classification in 2005 with Landsat 5 and the classification in 2016 with Sentinel 2 (Figure 5).

The transition matrix (Table 3 ) represents the percentage change in pixels for the two classes (Forest and No-Forest) between the two dates of 2005 and 2016.

According to the table, $70.044 \%$ of the forests classes and $75.652 \%$ of the no-forests classes remain stable the two dates of 2005 and 2016. During this 11 -year period, the analysis shows a significant deforestation (Forest $\rightarrow$ Non-Forest) of $29.956 \%$ but also regeneration (Non-Forest $\rightarrow$ Forest) of $24.348 \%$. The result is presented in Figure 6.

In terms of area, 16,687 ha of forest has been lost in 11 years. This means that there is a significant deforestation between two dates 2005 and 2016 (Table 4).

According to the Strategic Environmental and Social Assessment of Madagascar's REDD+ program, the annual deforestation rate for the rainforest ecoregion

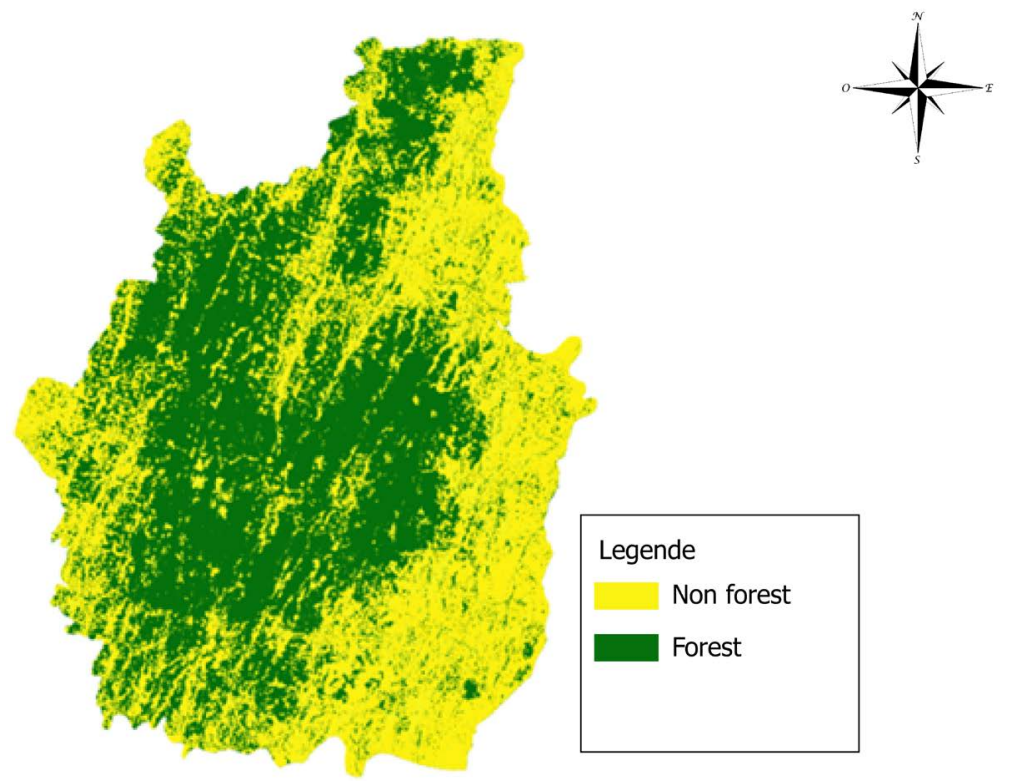

Figure 4. Classification with Random Forest.

Table 3. Transition matrix.

\begin{tabular}{crcc}
\hline \multirow{2}{*}{ Percentage of pixels per class } & \multicolumn{2}{c}{ Initial state (2005) } \\
\cline { 3 - 4 } & & Forest & No forest \\
\hline Final state & Forest & $73.044 \%$ & $24.348 \%$ \\
$(2016)$ & No forest & $26.956 \%$ & $75.652 \%$ \\
\hline
\end{tabular}

Table 4. Surface changed.

\begin{tabular}{ccc}
\hline Areas (Ha) & & \\
\hline Forest & $63,071.2$ & $46,383.3694$ \\
No forest & 1288.1636 & $17,975.9942$ \\
\hline
\end{tabular}


Classification in 2005 with LandSat 5
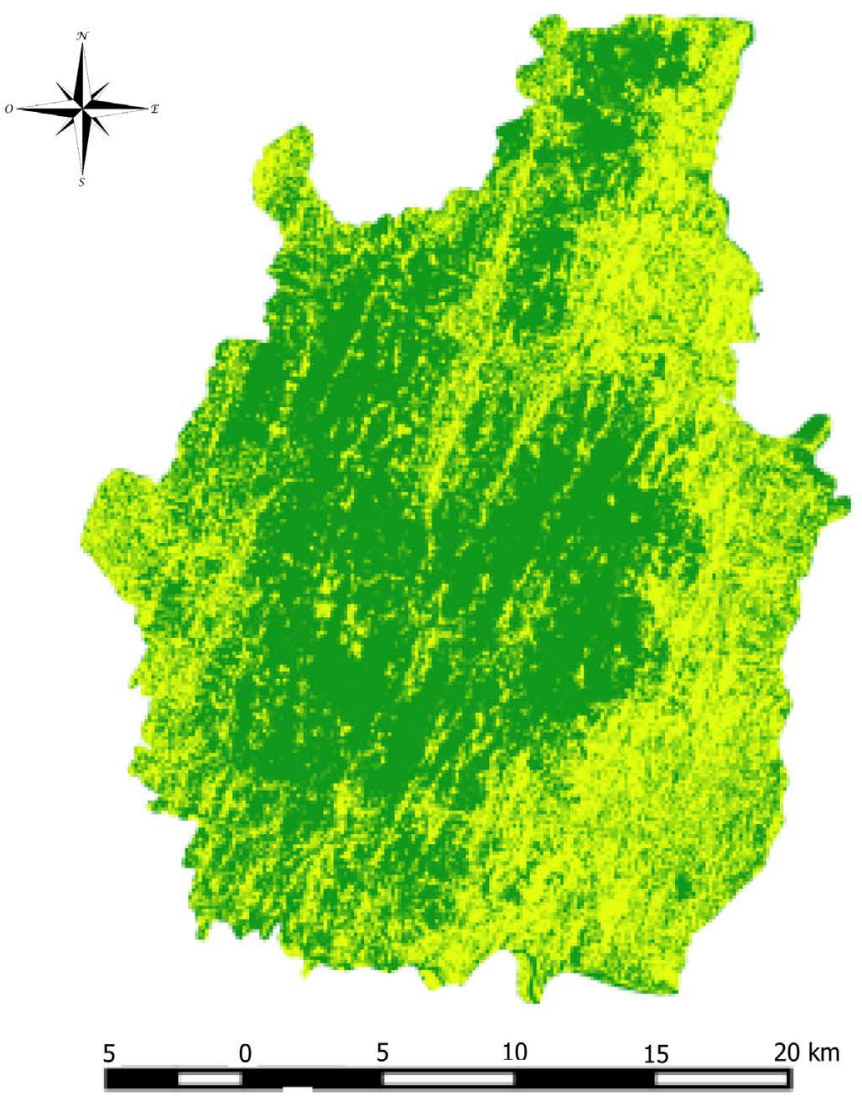

Classification in 2016 with Sentinel 2
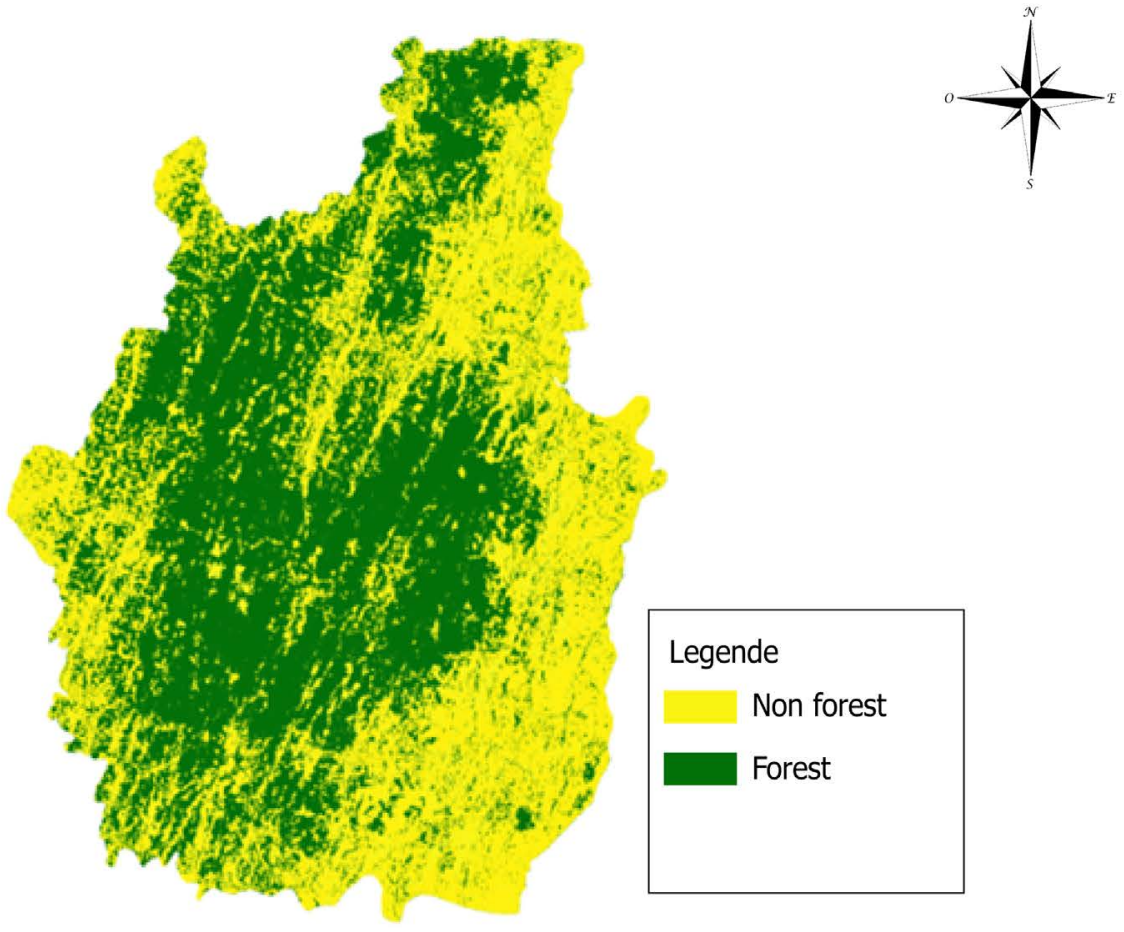

Figure 5. Classification results. 

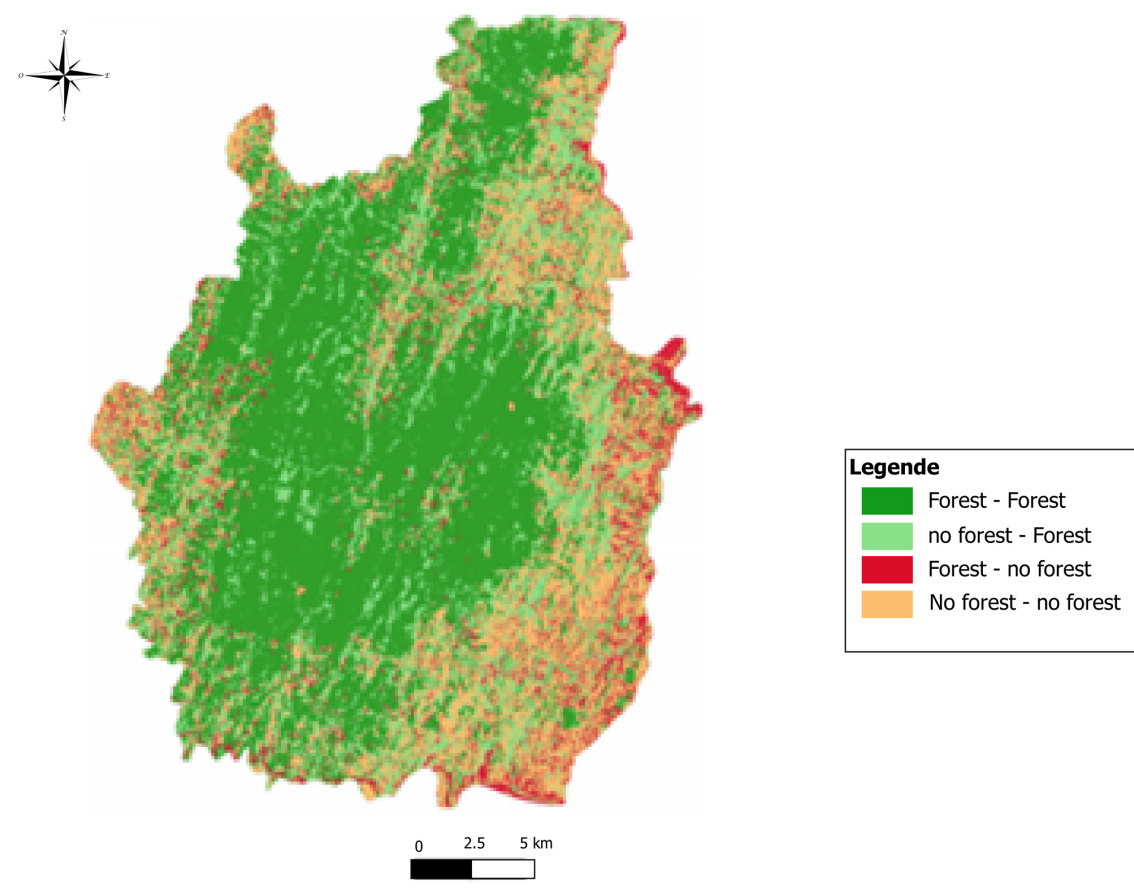

Figure 6. Change map.

in Madagascar is $0.94 \%$ per year for the period 2010-2013. The Analanjorofo region is found among the regions with the highest annual deforestation rate. In terms of area, the Analanjorofo region lost 24,000 ha of forest for the period 20102013. Surveys conducted by ONE in 2016 were able to group four root causes of deforestation and forest degradation: The weakness of governance and institutions, the non-rational use of forest resources and forest areas, the weak coordination of the development of rural areas to the detriment of forests and the rural poverty and the lack of alternatives development alternatives.

\section{Conclusion and Perspectives}

In this experience, we retain the technique of monitoring deforestation by remote sensing. This computerized solution is a facilitating means for experts in the field of environmental management that offers interesting results generally without direct contact to all the studied covers. We performed a supervised classification of a part of the National Park of Mananara Nord, in the commune of Antanambe by the satellite image Sentinel 2 acquired in 2016. This result is compared to a LandSat 5 classification in 2005 to detect the change between these two dates. The analysis shows the existence of more deforestation than generation in the study area. Deforestation monitoring mobilizes many entities in Madagascar. The results play a very important role for decision making in the field of environmental conservation in Madagascar. For this, the discussion is open for the capitalization of the experience in the form of knowledge that can be reused in another study area or other input data. The technique is applicable to a wider coverage such as the whole of Madagascar by inserting task automation 
(workflow) and parallel processing in the distributed system (cloud computing, grid computing) in order to optimize processing time.

\section{Conflicts of Interest}

The authors declare no conflicts of interest regarding the publication of this paper.

\section{References}

[1] Bouvier, M., Durrieu, S., Fournier, R.A. and Renaud, J.P. (2015) Generalizing Predictive Models of Forest Inventory Attributes Using an Area-Based Approach with Airborne LiDAR Data. Remote Sensing of Environment, 156, 322-334. https://doi.org/10.1016/j.rse.2014.10.004

[2] Giri, C. and Muhlhausen, J. (2008) Mangrove Forest Distributions and Dynamics in Madagascar (1975-2005). Sensors, 8, 2104-2117. https://doi.org/10.3390/s8042104

[3] Grinand, C., Rakotomalala, F., Gond, V., Vaudry, R., Bernoux, M. and Vieilledent, G. (2013) Estimating Deforestation in Tropical Humid and Dry Forests in Madagascar from 2000 to 2010 Using Multi-Date Landsat Satellite Images and the Random Forests Classifier. Remote Sensing of Environment, 139, 68-80. https://doi.org/10.1016/j.rse.2013.07.008

[4] Hajalalaina, A.R., Grizonnet, M., Delaitre, E., Rakotondraompiana, S. and Herve, D. (2013) Discrimination des zones humides en foret malgache, proposition d'une methodologie multiresolution et multisource utilisant orfeo toolbox. Revue Française de Photogrammétrie et de Télédétection, 201, 37-48. https://doi.org/10.52638/rfpt.2013.44

[5] Razafinimaro, A., Hajalalaina, A.R., Reziky, Z.T., Delaitre, E. and Andrianarivo, A. (2021) Landsat8 Satellite Image Classification with ERDAS for Mapping the Kalambatritra Special Reserve. American Journal of Remote Sensing, 9, 16.

[6] Waeber, P.O., Wilmé, L., Ramamonjisoa, B., Garcia, C., Rakotomalala, D., Rabemananjara, Z.H., Kull, C.A., Ganzhorn, J.U. and Sorg, J.P. (2015) Dry Forests in Madagascar: Neglected and under Pressure. International Forestry Review, 17, 127 148. https://doi.org/10.1505/146554815815834822

[7] WCS, ONE, MNP, ETC (2014) Analyse Historique de la déforestation: 2005-20102013.

https://bnc-redd.mg/images/documents/rapports/20170822/141210-FCC 051013 P ERR-FH 2014.pdf

[8] Gandhi, G.M., Parthiban, S., Thummalu, N. and Christy, A. (2015) Ndvi: Vegetation Change Detection Using Remote Sensing and Gis-A Case Study of Vellore District. Procedia Computer Science, 57, 1199-1210. https://doi.org/10.1016/j.procs.2015.07.415

[9] Ngom, R. and Gosselin, P. (2013) Development of a Remote Sensing-Based Method to Map Likelihood of Common Ragweed (Ambrosia artemisiifolia) Presence in Urban Areas. IEEE Journal of Selected Topics in Applied Earth Observations and Remote Sensing, 7, 126-139. https://doi.org/10.1109/JSTARS.2013.2254469

[10] Perumal, K. and Bhaskaran, R. (2010) Supervised Classification Performance of Multispectral Images. arXiv:1002.4046.

[11] Breiman, L. (2001) Random Forests. Machine Learning, 45, 5-32. https://doi.org/10.1023/A:1010933404324

[12] Dalmiya, C.P., Santhi, N. and Sathyabama, B. (2019) A Novel Feature Descriptor for 
Automatic Change Detection in Remote Sensing Images. The Egyptian Journal of Remote Sensing and Space Science, 22, 183-192.

https://doi.org/10.1016/j.ejrs.2018.03.005

[13] Stehman, S.V. and Foody, G.M. (2019) Key Issues in Rigorous Accuracy Assessment of Land Cover Products. Remote Sensing of Environment, 231, 111199. https://doi.org/10.1016/j.rse.2019.05.018

[14] Negassa, M.D., Mallie, D.T. and Gemeda, D.O. (2020) Forest Cover Change Detection Using Geographic Information Systems and Remote Sensing Techniques: A Spatio-Temporal Study on Komto Protected Forest Priority Area, East Wollega Zone, Ethiopia. Environmental Systems Research, 9, 1. 